\title{
Understanding R\&D in the arts, humanities and social sciences
}

\section{Hasan Bakhshi, Jonathan Breckon and Ruth Puttick}

Abstract: Despite much discussion and debate, research and development (R\&D) is still often considered as the domain of hard science and technology. Furthermore, it is not commonly known by industry and policymakers that the Organisation for Economic Cooperation and Development's (OECD) Frascati Manual - the internationally accepted methodology for collecting and reporting data on R\&D - formally recognises the arts, humanities and social sciences (AHSS) in R\&D. The UK collects data on R\&D using the Frascati Manual definition. However, arguably, what matters for the UK is how R\&D is defined for policy purposes. For example, the UK tax authorities choose to explicitly exclude AHSS R\&D from their definitions for the purpose of tax relief. This paper explores the role of AHSS R\&D in UK business. Drawing upon a review of the policy literature and interviews with 13 businesses that undertake AHSS research, and an additional 14 interviews with policymakers and other stakeholders, the paper presents recommendations for government, funders and business, and it concludes that more inclusive definitions and data are important for evidence-informed policy. Without the right definitions and tools to measure it and effective policies in place to support it, the Government risks ignoring the full value of R\&D in the UK economy, and missing out on incentivising investment in innovation in AHSS-related sectors and activities.

Keywords: R\&D, innovation, business, arts, humanities, social sciences.

Note on the authors: see end of article.

(C) The author(s) 2021. This is an open access article licensed under a

Creative Commons Attribution-NonCommercial-NoDerivs 4.0 Unported License 


\section{Introduction}

\section{Why this research matters}

This research is based on two premises. First, while the government recognises that the UK must increase its investment in research and development (R\&D) to address the UK's longstanding problem of low productivity, the contribution that research in the arts, humanities and social sciences (AHSS) disciplines makes to R\&D is not commonly understood. Consistent with this, this contribution does not translate into UK policymakers' R\&D definitions, and the model for R\&D statistics is structured toward STEM-based activities and so does not map effectively on to knowledge creation in the AHSS. There is a risk therefore of a 'gulf' between how and where R\&D happens and the policies that support it. ${ }^{1}$

Second, the UK economy is 80 per cent services based. ${ }^{2}$ This contains within it fast growing, internationally competitive sectors like the creative industries. The Government has a target of investing 2.4 per cent of GDP in R\&D by $2027,{ }^{3}$ with the aim of boosting the UK's innovation performance, increasing to 3 per cent thereafter. Understanding and measuring R\&D which has its origins in the AHSS in services may have vital significance for the 3 per cent target, and for the direction of policies to promote innovation and economic growth. ${ }^{4}$

Based on these two starting points, we might conclude that without the right definitions and tools to measure it and effective policies in place to support it, the Government risks ignoring the full value of R\&D in the UK economy, and missing out on incentivising investment in innovation in AHSS-related sectors and activities.

This report is a first step in filling the gap. Commissioned by the British Academy and conducted by Nesta and the Creative Industries and Policy Evidence Centre, it explores how UK businesses are investing in research and development (R\&D) in the AHSS.

\section{Methodology}

This qualitative research combined a rapid review of policy reports, alongside interviews with senior practitioners in UK business. We explored the published

\footnotetext{
${ }^{1}$ Bakhshi \& Lomas (2017); Nesta (2006; 2007).

${ }^{2}$ This figure pre-dates the COVID-19 pandemic (ONS 2020a).

${ }^{3}$ HM Government (2020).

${ }^{4}$ HM Government (2017). The Industrial Strategy Council (Balawejder \& Monahan 2020) has also argued that the UK needs to design more fit for purpose policies to support growth in the service sector.
} 
evidence to understand how the UK and other countries define, measure, and value R\&D involving the AHSS disciplines. To help delve deeper into the UK context, and to answer the question of how UK businesses invest in R\&D in the AHSS, we conducted interviews with 14 business leaders (from 13 businesses) and 14 representatives from relevant policy, university, charity, consultancy, creative and business organisations.

For the interviews with business, the sampling parameters included only UK-based business, or where there is a significant presence in the UK. As such, we actively recruited interviewees from beyond London, and England. We focused on companies within knowledge-based, services and cultural industries that might be associated with the arts, humanities, and social sciences. To identify the sectors most associated with AHSS, we used the Standard Industrial Classification codes, and drew upon the data which shows the quantity of AHSS graduates entering those sectors. ${ }^{5}$ To ensure a comprehensive range of business, we included both services and goods firms, and we also interviewed micro-businesses with less than nine employees and SMEs, to large multinationals. All interviews with business were conducted with senior staff who are responsible for, or have a significant awareness of, the firm's research and innovation activities.

The interviews were conducted between May and July 2020. Although this was during the difficult period of the COVID-19 lockdown, the interviewees were still willing to give their time. However, the COVID-19 crisis did hinder our ability to secure interviews with certain companies, such as those in manufacturing. To give a rounded view therefore, we also interviewed 14 representatives of organisations with an interest in R\&D policy, such as the OECD, Centre for Evidence Based Management, and the R\&D tax consultancy, ForrestBrown. Some of our interviewees were representatives of charitable or public bodies, such as the Royal Shakespeare Company and the $\mathrm{BBC}$, but we interviewed staff from their commercial and enterprise arms. Conversely, some businesses we interviewed had charitable arms that use AHSS R\&D, such as Chelsea Football Club.

All the interviews were semi-structured, with a question guide used as an aide-mémoire. Detailed notes were taken during the interview, including verbatim quotes, to ensure accuracy in our analysis. A full list of the interviewees is available in the Appendix.

\footnotetext{
${ }^{5}$ British Academy (2020).
} 


\section{The research questions}

Through a mix of desk research and interviews, the report addresses the following questions:

1. How is research and development (R\&D) conceived of in the service and creative industries, and other sectors most closely related to arts, humanities, and social sciences?

2. How is $R \& D$ data in the sectors related to arts, humanities, and social sciences defined and counted in the UK?

3. Does UK R\&D data collection adequately recognise $R \& D$ activities taking place in the sectors related to AHSS, and does this vary by industry?

4. If $R \& D$ is not captured in the official statistics, why is this the case and what are the implications for business and innovation policy?

\section{The contribution of AHSS to innovation and growth}

The AHSS cover a wide range of research disciplines, including archaeology, design, economics, linguistics, history, music, psychology, and philosophy. They contribute to a constantly growing body of knowledge on human experience, agency, identity and expression, helping inspire creative behaviour, as well as novel goods and services. ${ }^{6}$ Alongside providing new ideas that can be applied directly in the generation and adoption of innovations, AHSS research shines a spotlight on the ethical foundations of the innovation system. As Bakhshi \& Lomas note, 'if good ideas are to be picked up by society, then they must be mindful of different systems of culture and governance as well as respecting local structures of motivation and belief'?

Yet, the role and impact of AHSS to R\&D is not explicit in the business sector. ${ }^{8}$ Kahn (2010) argues that the very definition of what constitutes the social sciences and humanities is ill-defined. Although there is the OECD's FORD classification (see below), Kahn claims that there is no clear and universally accepted definition of what constitutes the social sciences and humanities, and that it is problematic to segment the two. Although he is focused on social sciences and the humanities, arguably the same issues extend to defining and isolating 'the arts'. What's more, the

${ }^{6}$ See for example, Morgan Jones et al. (2020); Bakhshi et al. (2008); Walker (2015); and Bakhshi \& Lomas (2017).

${ }^{7}$ Bakhshi \& Lomas (2017).

${ }^{8}$ Kahn (2010). 
definition of AHSS is evolving. The rapid shifts in the boundaries of disciplines means that regular reviews of discipline boundaries may be required. ${ }^{9}$

Overall, empirical research on how businesses engage in, understand and utilise AHSS R\&D has been limited. However, gaps are starting to be filled. For example, recent research and a set of insightful case studies from the Academy of Social Sciences has identified the central role that knowledge and skills from the social sciences play in UK businesses. ${ }^{10}$

\section{OECD and international approaches to AHSS R\&D}

Key messages:

- The most recent revision of the OECD's Frascati Manual (2015) acknowledges the importance of R\&D in AHSS.

- For activity to be classified as R\&D by the Frascati Manual, it must meet five criteria: novel; creative; uncertain; systematic; and transferable and/or reproducible.

- For AHSS R\&D, focusing on novelty and uncertainty is according to the Frascati manual 'extremely helpful' for defining the boundary between R\&D and more routine research activities.

- The OECD's compendium of international tax incentives reported that the following countries permit humanities and social sciences $R \& D$ within their $R \& D$ Tax Credit programmes: Austria, Belgium, Chile, Colombia, Denmark, France, Hungary, Italy, Korea, Mexico, Norway, Portugal, Russia, and Spain.

\section{The OECD's Frascati Manual now recognises AHSS research}

To define R\&D, we use the OECD's Frascati Manual, the internationally recognised methodology for collecting and reporting data on R\&D. ${ }^{11}$ Now in its seventh edition, the Manual is used by policymakers, statisticians, academics, and others, to help standardise the data collection guidelines and classifications for compiling R\&D statistics. $^{12}$

\footnotetext{
${ }^{9}$ Kahn (2010).

${ }^{10}$ Lenihan et al. (2020).

${ }^{11}$ Bakhshi \& Lomas (2017).

${ }^{12}$ OECD (2015: 44-5).
} 
While arguably it needs to go further, ${ }^{13}$ in successive revisions the Frascati Manual has evolved to recognise AHSS R\&D. This is something that many policymakers and businesses in the UK may not be aware of as activity deriving from AHSS is not generally recognised as a form of R\&D in fiscal policy (see below). In contrast with previous editions, the most recent Frascati Manual (2015) acknowledges explicitly the importance of R\&D in AHSS, saying:

R\&D is found in the social sciences, humanities and the arts as well as in the natural sciences and engineering. This manual gives greater emphasis than past editions to the social sciences, humanities and the arts. This requires no changes in the definitions and conventions but it does require greater attention to the boundaries that define what is and what is not R\&D. ${ }^{14}$

The OECD offers illustrative examples in cases like economics (the development of a novel method to manage an investment fund), history (the design of a new museum exhibit that serves as a prototype for other museums), linguistics (the development of a new tool for diagnosing autism in children based on their language acquisition, retention and use of signs) and music (the development of new pedagogical materials based on new discoveries in neuroscience).

Within the Frascati Manual, the OECD Fields of Research and Development (FORD) classification scheme assists with R\&D measurement. Where the content of the R\&D subject matter is closely related, subjects are grouped to form broad (onedigit) and narrow (two-digit) fields of classification. Table 1 shows the R\&D activities for AHSS (OECD 2015: 59).

In some ways, the recent clarifications around the scope of $R \& D$ in revisions of the Frascati Manual mark a catching up with revisions to the Oslo Manual, the OECD's guidelines for the collection, reporting and use of data on innovation (now in its fourth revision), which since its inception in 2002 has recognised a wider range of innovation-related phenomena, but not $\mathrm{R} \& \mathrm{D}$, which is the domain of the Frascati Manual. ${ }^{15}$ The Frascati Manual's acknowledgement of AHSS R\&D is significant because despite policymakers' acceptance that innovation is a broad phenomenon, $\mathrm{R} \& \mathrm{D}$ remains the primary focus of innovation policy. ${ }^{16}$

Whilst the recognition of AHSS in the Frascati Manual is welcome, it should not be overstated as there is still a strong focus on science and technology. Bakhshi \&

\footnotetext{
${ }^{13}$ Bakhshi \& Lomas (2017).

${ }^{14}$ Bakhshi \& Lomas (2017) argue that the Frascati Manual needs to go further in recognising R\&D in the AHSS; in particular, in its treatment of uncertainty (which should embrace forms of uncertainty that are not fully resolved through experimentation) and in the need to acknowledge knowledge creation which involves production of experiences and behavioural change as well as that which produces products.

${ }^{15}$ OECD \& Eurostat (2019).

${ }^{16}$ HM Treasury \& HMRC (2020).
} 
Table 1. R\&D activities for AHSS, adapted from OECD (2015).

\begin{tabular}{ll}
\hline Broad classification & Second-level classification \\
\hline 5. Social Sciences & 5.1 Psychology and cognitive sciences \\
& 5.2 Economics and business \\
& 5.3 Education \\
& 5.4 Sociology \\
& 5.5 Law \\
& 5.6 Political science \\
& 5.7 Social and economic geography \\
& 5.8 Media and communications \\
& 5.9 Other social sciences \\
& 6.1 History and archaeology \\
6. Humanities and the arts & 6.2 Languages and literature \\
& $6.3 \mathrm{vPhilosophy,} \mathrm{ethics} \mathrm{and} \mathrm{religion}$ \\
6.4 Arts (arts, history of arts, performing arts, & music) \\
& \\
\hline
\end{tabular}

Lomas (2017) argue that considerably more still needs to be done in future revisions to rebalance the Frascati Manual's emphasis beyond science and technology to better capture the contribution the AHSS make to R\&D. ${ }^{17}$

\section{The five criteria of the Frascati Manual R\&D - and its relevance to AHSS}

The Frascati Manual defines R\&D at its most general as:

Research and experimental development (R\&D) comprise creative and systematic work undertaken in order to increase the stock of knowledge - including knowledge of humankind, culture and society - and to devise new applications of available knowledge.

R\&D so defined covers three types of activity (OECD 2015: 45):

Basic research is experimental or theoretical work undertaken primarily to acquire new knowledge of the underlying foundations of phenomena and observable facts, without any particular application or use in view. Applied research is original investigation undertaken in order to acquire new knowledge. It is, however, directed primarily towards a specific, practical aim or objective. Experimental development is systematic work, drawing on knowledge gained from research and practical experience and producing additional knowledge, which is directed to producing new products or processes or to improving existing products or processes.

${ }^{17}$ Bakhshi \& Lomas (2017). 
For activity to be classified as R\&D, it must further meet five criteria, defined by the OECD (2015: 45) as being:

- novel

- creative

- uncertain

- $\quad$ systematic

- transferable and/or reproducible.

'Novel' relates to building new knowledge and 'creative' requires there to be an intentional objective to acquire new knowledge through R\&D. In the business sector, novelty has to be assessed by comparison with the existing stock of knowledge in the industry. Research cannot purely recycle existing research - although it can attempt to replicate an existing result (OECD 2015: 46). The Frascati Manual (OECD 2015: $47-9,81$ ) deals with 'uncertainty' in only a minimal way. In the case of basic research, the OECD recognises that it might not be possible to reach clear results. For example, research may not be able to rule out a range of competing hypotheses (OECD 2015: 47). Uncertainty can also mean that it is difficult to predict costs and final outcomes in developing a new business initiative. But there is still an expectation that the work will be 'planned and budgeted' - and be 'Systematic', with records kept of both the processes undertaken, and outcomes achieved (OECD 2015: 49). Systematic within the context of the wider scientific literature, however, has a more rigid definition which implies a precisely defined approach to research which minimises bias, such as in systematic reviews and meta-analyses ${ }^{18}$. But this is not intended in the Frascati Manual. Finally, the requirement that research in R\&D should be 'transferable and/ or reproducible' (OECD 2015: 48-9) refers to the requirement that new knowledge does not remain tacit but is conveyed to others, for example in a peer reviewed academic article. However, the examples given in the Manual are limited.

One of the key principles in the Frascati Manual is ruling out R\&D activities that are regarded as routine. For AHSS, focusing on novelty and uncertainty 'is extremely helpful' for defining the boundary between $\mathrm{R} \& \mathrm{D}$ and more routine research activities (OECD 2015: 74). For instance, using annual labour force surveys is not applicable. But an economic case study on a particular region, perhaps using novel data collection techniques, that are 'integral' to the project, is acceptable (OECD 2015: 74). For the arts and humanities, the OECD recommends focusing on three of the five core criteria (novelty, creativity, transferability/reproducibility) although no detailed reasons are given for especially focusing on these (OECD 2015: 74).

\footnotetext{
${ }^{18}$ Higgins \& Green (2008).
} 
This OECD definition further stresses that R\&D should not be confused with other approaches used in the university and funding communities, such as knowledge mobilisation or knowledge exchange. $\mathrm{R} \& \mathrm{D}$ involves the three types of activity (basic research, applied research, and experimental development) and must meet the five Frascati criteria (novel; creative; uncertain; systematic; and transferable and/or reproducible). And it is not synonymous with innovation, the preserve of the Oslo Manual. Innovation may, for example, occur without any R\&D.

It should be noted, however, that the Frascati $R \& D$ definition is framed in terms of knowledge creation, not of who is doing the $\mathrm{R} \& \mathrm{D}$, so it cuts in principle across all sectors - not just business enterprises - but also R\&D conducted in government, higher education, and private non-profit organisations.

\section{International definitions of R\&D tax incentives schemes that include AHSS}

Although the Frascati Manual is the main reference point for defining R\&D internationally, what is defined as $\mathrm{R} \& \mathrm{D}$ varies between countries and their tax incentives across the world. In the OECD's compendium of international tax incentives member states report on whether the humanities and social sciences are eligible for R\&D tax relief. In 2018 (the latest data available at the time of writing), the following OECD countries were permitting Social Science and Humanities (SSH) R\&D within their R\&D Tax Credit programmes: ${ }^{19}$

$\begin{array}{ll}\text { Austria } & \text { Italy } \\ \text { Belgium } & \text { Korea } \\ \text { Chile } & \text { Mexico } \\ \text { Colombia } & \text { Norway } \\ \text { Denmark } & \text { Portugal } \\ \text { France } & \text { Russia } \\ \text { Hungary } & \text { Spain }\end{array}$

${ }^{19}$ OECD (2019). 


\section{AHSS R\&D is excluded from key areas of policy in the UK}

Key messages:

- R\&D involving research in the AHSS is explicitly excluded in some areas of policy by organisations such as the Department for Business, Energy and Industrial Strategy, Her Majesty's Revenue \& Customs (HMRC), and Her Majesty's Treasury (HMT).

- Although the UK is not alone in excluding work in the AHSS, this feature of UK policymakers' application of the definition of R\&D means that UK fiscal policy does not recognise the role that AHSS R\&D plays in delivering innovation, productivity and growth, and the role that tax relief can play in incentivising $R \& D$ which has its origins in the AHSS disciplines.

- In 2020, HMT and HMRC consulted on the scope of qualifying expenditures for R\&D tax relief. There is no indication that this includes AHSS, although there is reference to two broad areas that are relevant for AHSS R\&D: data analysis and cloud storage.

It is often claimed that UK policymakers use the Frascati Manual definition of R\&D, however in reality - as in other OECD countries - it is down to how the UK adopts the definition for policy purposes. For example, the UK authorities choose to exclude AHSS from their definition of R\&D for R\&D tax relief purposes. $R \& D$ is defined in section 1138 of the Corporation Tax Act 2010 as 'activities that fall to be treated as research and development in accordance with generally accepted accounting practice. ${ }^{20}$ However, this legislation is subject to any regulations made by Her Majesty's Treasury (HMT), and any detailed guidance provided by the Department for Business, Energy and Industrial Strategy (BEIS). BEIS says in its Guidelines on the Meaning of Research and Development for Tax Purposes: 'science is the systematic study of the nature and behaviour of the physical and material universe. Work in the arts, humanities and social sciences, including economics, is not science for the purpose of these Guidelines. ${ }^{21}$

In addition, the application and interpretation of this definition is driven by Her Majesty's Revenues \& Customs (HMRC) which is also explicit about only focusing on science and technology, and excluding 'work in the arts, humanities and social sciences (including economics)'. ${ }^{22}$

\footnotetext{
${ }^{20}$ HM Government (2010).

${ }^{21}$ BIS (2010).

${ }^{22} \operatorname{HMRC}$ (2015: 12).
} 
This means that R\&D expenditures relating to AHSS are actively excluded from $R \& D$ tax incentives in the UK, even if they otherwise satisfy the requirements of R\&D. ${ }^{23}$ Although the UK is by no means alone in excluding work in the arts, humanities and social sciences (see section above on the practice in other OECD countries), this feature of the UK's application of the definition of R\&D means that UK fiscal policy does not recognise the role that AHSS R\&D plays in delivering innovation, productivity and growth, ${ }^{24}$ and the role that tax relief can play in incentivising R\&D which has its origins in the AHSS disciplines. ${ }^{25}$

\section{UK R\&D Tax Credits}

R\&D tax credits are a tax relief 'designed to encourage greater R\&D spending, leading in turn to greater investment in innovation'. They work by reducing a company's taxable income by an amount equal to a percentage of the company's allowable R\&D expenditure, thereby incentivising $\mathrm{R} \& \mathrm{D}$ over other forms of business investment. The rationale for doing so is one of market failure: research suggests that $R \& D$ investment generates positive externalities on businesses not undertaking the investment, implying that in the absence of policy intervention the overall amount of R\&D undertaken will be below what is socially optimal. The tax relief on R\&D has been considerably extended over the last decade through a number of recent announcements. Some key recent milestones are shown in Table 2.

Table 2. Key recent milestones in the extension of tax relief on R\&D.

\begin{tabular}{ll}
\hline $2000-01$ & Tax credits for companies investing in R\&D were introduced for SMEs \\
$2002-03$ & Extended to larger companies \\
$2003-05$ & $\begin{array}{l}\text { Extended for vaccine research } \\
\text { Increase in rates of enhanced deductions for both large companies and SMEs; and } \\
\text { definition of a SME changed to include more 'large' companies }\end{array}$ \\
$2011 \& 2012$ & $\begin{array}{l}\text { The rate of enhanced reduction was further increased for SMEs } \\
2013\end{array}$ \\
2014 & Introduction of Research and Development Expenditure Credit (RDEC) scheme \\
2016 & Package of measures to streamline the R\&D tax credits application process \\
2018 & Large Company Scheme replaced \\
2019 & Updated guidance on software R\&D - resulting in more challenges on software claims \\
2020 & Changes to process of claims to include full corporation tax computation \\
April 2021 & HMT/HMRC Consultation on scope of qualifying expenditure \\
\hline
\end{tabular}

\footnotetext{
${ }^{23}$ Bakhshi \& Lomas (2017).

${ }^{24}$ Bakhsh \& Lomas (2017).

${ }^{25}$ Creative Industries Council (2020).
} 
The total R\&D claimed in 2016-17 was $£ 4.4 \mathrm{bn}$ - claims made against $£ 32.8 \mathrm{bn}$ of $\mathrm{R} \& \mathrm{D}$ - in over 7,000 businesses. To qualify for relief, activities are limited to staff costs, consumables, certain types of software, payments to clinical trials subjects and, depending on the scheme, some subcontracting costs.

In 2020, HMT and HMRC consulted on the scope of qualifying expenditures for $\mathrm{R} \& \mathrm{D}$ tax relief. There was no indication that this included AHSS, although there was reference to two broad areas that are relevant for AHSS R\&D: data analysis and cloud storage. ${ }^{26}$

\section{The UK's R\&D survey instruments recognise AHSS R\&D, but in practice likely under-count it}

Key messages:

- The UK uses the OECD's Frascati definition when collecting R\&D data, and therefore AHSS R\&D is in principle captured in official statistics such as the Office for National Statistics's (ONS) Business Enterprise R\&D survey or the UK Innovation Survey.

- However, AHSS R\&D is likely severely undercounted. If official bodies such as BEIS, HMRC, and HMT are explicit about excluding AHSS from their definitions it is less likely that businesses will record this type of $R \& D$ and therefore include it in statistical returns.

- Other limitations of official business surveys include the lags between data collection and data publication and between new sectors emerging and their appearance in industrial classifications. The internationally agreed Standard Industrial Classification (SIC) codes are only revised after long intervals (at least ten years in recent years) and may not capture emerging sectors, some of which, like virtual reality, can be expected to be heavy investors in AHSS R\&D.

- We need to look beyond traditional measured $R \& D$ to provide a full account of investment in innovation.

${ }^{26}$ HM Treasury \& HMRC (2020). 
In the UK, the Office for National Statistics (ONS) uses the Frascati Manual definition of $R \& D$ to collect $R \& D$ statistics, and uses these to publish the following five $R \& D$ datasets: $:^{27}$

1. Business Enterprise $R \& D(B E R D)$ : annual $\mathrm{R} \& \mathrm{D}$ spending and employment by UK businesses, including by industry type, civil and defence, and regional spread.

2. UK Innovation Survey (UKIS): a biennial survey undertaken by ONS on behalf of BEIS to assess innovation activity.

3. Government Expenditure on Science, Engineering and Technology: Science, engineering and technology (SET) annual expenditure by UK government departments, research councils and higher education funding councils.

4. Gross Domestic Expenditure on $R \& D$ (GERD): Annual estimates of R\&D spending in the UK of research and development by business enterprise, higher education, government, research councils and private non-profit organisations.

5. Statistical Release on Tax Relief: Beyond R\&D data collection, but worth noting here, is the statistical release on R\&D tax relief, published each year, to detail the costs to the Exchequer of providing R\&D tax relief. ${ }^{28}$

The first two R\&D data sets are discussed in more detail below before discussing some of their limitations.

\section{Business Enterprise R\&D (BERD)}

Using the Frascati definition of R\&D, the ONS captures expenditure on R\&D by asking businesses about their R\&D expenditure. The annual BERD survey samples approximately 5,500 businesses in the UK. From this sample, estimates of overall spending on R\&D performed by UK businesses, and the characteristics of businesses undertaking those activities, are calculated. The ONS regularly reviews the coverage of firms to ensure it is capturing R\&D-intensive firms and sectors. ${ }^{29}$ Total UK R\&D expenditure rose by $£ 2.3$ billion to $£ 37.1$ billion in 2018 ; this was an increase of 6.6 per cent, which was larger than the 4.8 per cent growth in 2017 and the largest annual rise since 2013. This equates to 1.7 per cent of gross domestic product (GDP), but remains below the EU (EU-28) provisional estimate of 2.1 per cent. ${ }^{30}$ The ONS also collects data on firm size. It reports that spending on R\&D by small and medium-sized

\footnotetext{
${ }^{27}$ ONS (2019b).

${ }^{28}$ HMRC (2019).

${ }^{29}$ Athow (2019).

${ }^{30}$ ONS (2020b).
} 
enterprises broadly trebled from 2007 to 2017. While this is a large increase, SME expenditure on R\&D only accounts for 3 per cent of the total. ${ }^{31}$

Within the BERD statistical release, several methodological points are raised. The BERD survey reports:

... on R\&D expenditure in UK businesses irrespective of the country of residence of the ultimate owner or users of the $R \& D$ produced. $R \& D$ is measured by the expenditure on R\&D performed by a business, or the funding received by a business for R\&D work. These are often but not always the same. Performance is regarded as a more accurate measure than funding received by a business, as not all funds received may be used as intended. ${ }^{32}$

The types of R\&D covered by the BERD survey are presented in the detailed product groups that the ONS makes available alongside the industrial sectors that are covered. The product group AF 'Research and development services' maps across to the Standard Industrial Classification (SIC) code 7220 Research and experimental development on social sciences and humanities (though not the arts) so R\&D in AHSS by specialist SSH companies (that is, organisations whose primary activity is identified as being within SSH R\&D) is covered. The latest available BERD estimates suggest that in 2018 these firms invested $£ 120$ million in $R \& D{ }^{33}$

\section{UK Innovation Survey (UKIS)}

To capture detailed information on business $R \& D$ and performance, and on complementary innovation activities (such as skills development, design and investment in absorptive capacity), the ONS conducts the UKIS on behalf of BEIS. This survey is completed by a sample of UK businesses (just over 14,000 in UKIS 2019) with at least ten employees. Businesses report on their internal and external R\&D expenditure using the Frascati definition, alongside other metrics, so again some AHSS R\&D should in principle be covered. The UKIS contributes to the Europeanwide Community Innovation Survey (CIS) to allow for international benchmarking and comparisons. ${ }^{34}$

\footnotetext{
${ }^{31}$ Athow (2019).

${ }^{32}$ ONS (2019c).

${ }^{33}$ ONS (2020c).

${ }^{34}$ BEIS (2020).
} 


\section{Limitations of efforts to measure R\&D}

A theoretical criticism of $\mathrm{R} \& \mathrm{D}$, however defined, is that it is an incomplete conceptualisation of how firms invest in innovation. In particular, for several decades there has been criticism of the so-called linear model of innovation with its traditional emphasis on science and technology indicators. ${ }^{35}$ Published in 2006, Nesta's report, The Innovation Gap, highlighted how R\&D definitions ignored 'hidden innovation' - the innovation activities that are not reflected in traditional $R \& D$ and innovation metrics. ${ }^{36}$ This was followed a year later with the report, Hidden Innovation, which uncovered important innovation activities across six sectors viewed as 'low innovation' sectors using traditional indicators. ${ }^{37}$ It argued that developing relevant metrics for investment in hidden innovation was essential for evidence-based policy making. More recently, Nesta's Innovation Inde ${ }^{38}$ used a more inclusive measure, and revealed that science and technology R\&D investment represented just 12 per cent of total investment in innovation in the UK, reinforcing the need to look beyond traditional R\&D metrics when providing a full account. ${ }^{39}$

\section{Self-reporting on $R \& D$ is problematic}

Asking businesses to self-report on R\&D activity and expenditure is notoriously challenging. Kahn (2010) argues that 'The greyness of the definitions and boundaries means that R\&D surveys are more complex than, say, health or education surveys they involve a great deal of estimation and approximation, especially as they are retrospective. It is 'easy' to count desks or schools, or record infant deaths. In contrast, the subjects of R\&D surveys are unique, whether these are firms, universities or research institutes, and the quality of their institutional information systems is crucial for generating accurate data'. As an example, it is claimed that GERD is compiled to an accuracy of 10-15 per cent (Kahn 2010).

If official bodies such as BEIS, HMRC, and HMT are explicit about excluding AHSS from their definitions, as outlined above, it is less likely that firms will record this type of R\&D in the collection of statistics (an obvious area for further testing with businesses). Moreover, our interviews with businesses flagged up that in several cases they did not themselves identify their AHSS work as R\&D, which is likely to lead to it being under-counted as such. This would be consistent with the figures

\footnotetext{
${ }^{35}$ Nesta (2006).

${ }^{36} \mathrm{Nesta}(2006)$.

${ }^{37}$ See also Nesta (2008).

${ }^{38}$ Goodridge et al. (2014).

${ }^{39} \mathrm{~d}$ 'Angelo et al. (2018).
} 
implicitly reported for AHSS R\&D by non-specialist HSS R\&D businesses in the BERD survey being too low - something which cannot readily be established as the BERD questionnaire does not ask businesses to identify separately their AHSS R\&D (unlike specialist HSS companies as mentioned earlier).

SIC codes paint an imperfect picture of where $R \& D$ happens and miss emergent sectors

As with all official business surveys, business spending on R\&D is coded to the internationally set Standard Industrial Classification (SIC) codes. The main strength of these codes is that they enable historical and international comparisons. However, a disadvantage is that they are reset at very low frequencies (at least decadal in recent years) and as such do not adequately reflect new industries and sectors, such as Artificial Intelligence (AI) or immersive technologies like Virtual Reality (VR). ${ }^{40}$ Inaccuracies in the SIC codes can therefore make it difficult to correctly identify the sectors within which R\&D is being undertaken, and hinder targeted efforts by the government to support it, such as Industrial Strategy R\&D programmes which have a sectoral focus.

In addition, small businesses are not always well covered in sources like the BERD and UKIS surveys. While in most sectors this may be justified on the grounds that small businesses account for only a small amount of R\&D activity in industry (ref. the earlier statistic that SMEs account for only 3 per cent of total BERD), this may not necessarily be the case in sectors like the creative industries nor for all forms of R\&D. A case in point is AHSS, where arguably more human- and less capital-intensive forms of R\&D lend themselves to smaller units of organisation - consider as an example the UK's long tail of small design agencies. ${ }^{41}$ Relatedly, such forms of R\&D may also involve R\&D activities by contracted consultants and other types of freelancer which may also point to a more significant role for smaller businesses in AHSS R\&D.

\section{Time lags delaying data publication}

As in other countries, another issue with official business R\&D surveys is the time required to collect and make publicly available the data. At the time of writing, the most recent version of the UKIS, for example, was published in 2018 and refers to the period 2014 to 2016. Open data sets such as UKRI's Gateway to Research data have become available which permit independent estimates to be produced of publicly funded R\&D activity and which in principle are also more timely, but equivalent data sources for privately funded $R \& D$ are much more difficult to find.

\footnotetext{
${ }^{40}$ Nesta (2019).

${ }^{41}$ Design Council (2018); Bakhshi et al. (2009).
} 


\section{Insights from business: arts, humanities, and social sciences R\&D}

This section forms the empirical part of this article presenting the findings from our interviews with 14 business executives from 13 companies - and other representatives from universities, charities, consultancy, creative and business bodies (see Appendix).

Key messages:

- Our interviews suggested that the Frascati definition of R\&D resonates with businesses and was applicable to their work.

- However, in several cases the businesses did not themselves describe their AHSS work as R\&D at all - but might label it 'innovation', 'experimentation' or 'use of research evidence' instead.

- A sustained theme was the interconnectedness of AHSS and STEM R\&D.

- One potential way of seeing social science business R\&D is through a broader lens of evidence-based business and management.

- Although market research is excluded from definitions of R\&D, some market research involving AHSS is experimental and methodologically sophisticated and could meet the Frascati R\&D criteria.

- Businesses should recognise AHSS R\&D as R\&D and measure it.

- Many interviewees highlighted the need for there to be better awareness of what AHSS R\&D is, and the value it brings. AHSS R\&D is perceived to be challenging to measure as it is often perceived to be less 'tangible' than STEM R\&D.

- Businesses identified the value of R\&D in helping to address social and environmental changes. They explained that they were using AHSS to pursue social missions, such as using research insights to reduce inequality or adverse environmental impacts.

- Businesses were clear that government support for AHSS R\&D was essential, both through R\&D tax relief, and by other policy interventions.

\section{The interconnectedness of AHSS and STEM}

R\&D, including both STEM and AHSS, was widely described by many interviewees as central to their innovation processes. Interviewees emphasised that we should avoid viewing R\&D as a 'nice to have' or a 'vanity project'. Instead, it needs to be normalised into business practices.

A sustained theme was the interconnectedness of AHSS and STEM R\&D. For example, Sandy Smith at Pearson plc, said that in their R\&D efforts there was not a clear difference between R\&D from AHSS and from other areas. He warned against 


\section{Using language data to help brands interact and communicate more effectively with their audiences}

Relative Insight was born out of a 10-year research project in Lancaster University's linguistic and cybersecurity departments. It has worked with companies like John Lewis, Prudential and McCann. Originally designed to analyse data to help law enforcement agencies identify criminals masquerading as children in chat rooms, Relative Insight has continued to develop the technology to analyse how people speak, to help companies create sharper strategy and communication with their target audiences. Relative Insight's platform has been used by many advertising and marketing agencies, in the UK and overseas. Ben Hookway, Relative Insight's CEO describes it as deriving value from language; he says that they provide technology and analytics that reveal the dynamics of language, interrogate its meaning and interpretations, engage with people, and influence behaviour.

What is central to Relative Insight is the interconnectedness between AHSS and STEM R\&D. Rather than R\&D being purely AHSS, or conceptualising linguistics as solely the domain of the social sciences, Relative Insight, develops and applies technology and analytical capabilities, to blend linguistics with mathematics and other areas of STEM.

setting up AHSS R\&D and STEM R\&D as distinct and different activities, comparing this with research debates surrounding the value of quantitative compared with qualitative research, when what was needed were mixed methodologies. This was echoed by other companies which did not differentiate between different sources of knowledge in their R\&D efforts, with STEM and AHSS R\&D co-existing, and often in a symbiotic relationship. The interviewee from Zinc went as far as saying that they use the term 'human sciences' to stress the interdisciplinary nature of their work.

Behavioural science, language and linguistics research, AI, data science, cybersecurity, design research, and creative digital $R \& D$ are all interdisciplinary in nature and bridge AHSS with technology and science. They are vital areas of business innovation that can provide the UK with competitive advantage. Even in firms which might be regarded as having an emphasis on life sciences or engineering in their R\&D, there are overlaps with AHSS. Keith Rutherford, Vice-President R\&D Home and Hygiene at Unilever told us that both AHSS and STEM were equally important to them:

I would go so far to say that a lot of our research into sustainable products is $50: 50$ [between STEM and AHSS], seeking to understand macro-trends, societal and consumer needs in addition to all the evident technical challenges. You may think it's obvious, but unless you solve the real consumer tension then products will end up sitting on shelves. The shift to sustainable consumption, is that psychology, art and design or chemistry? It is all of these and we must never underestimate the 'theatre' of the consumer experience, the 'Click' of the Eco-Refill when it attaches to the bottle is crucially important in driving adoption. 


\section{Businesses should recognise AHSS as R\&D and measure it}

In our interviews we explored how UK businesses define and conceptualise R\&D, using the OECD's Frascati definition as a prompt.

Our interviews suggested that the Frascati definition of R\&D resonated with businesses and was applicable to their work. However, they did not always use the language of the Frascati Manual, and in several cases the businesses did not themselves describe their AHSS work as R\&D at all - but might label it 'innovation', 'experimentation' or 'use of research evidence' instead. These businesses were more familiar with other definitions and terms - partly reflecting funding sources and universities, including concepts like 'knowledge exchange' or 'evidence-based management'.

An implication is that these businesses do not include investment in AHSS R\&D in their R\&D budgets. And businesses whose R\&D activities are dominated by AHSS may not have an R\&D budget at all. In this context, it is striking that in a Department for Digital, Culture, Media and Sport (DCMS) survey of R\&D in the creative industries, only 8 per cent of respondents said they had a formal budget for R\&D despite 55 per cent claiming they invest in it. ${ }^{42}$ As well as making it difficult to fully account for AHSS R\&D in company accounts - and in official survey statistics - the omission of AHSS R\&D from dedicated R\&D budgets risks its potential long-term importance to the innovation performance of a firm being neglected.

But there were significant exceptions to this lack of R\&D terminology: some businesses explicitly used the language of R\&D when describing their work with the AHSS. Interviewees at the BBC, Royal Shakespeare Company, Unilever, Zinc and AWA, all had R\&D in their job, departmental or project titles. For some organisations we interviewed, like multinational consumer goods company Unilever and the global healthcare business Novartis, R\&D is at the heart of their business strategy. Such businesses traditionally think of R\&D in terms of developing a new product, such as a drug or a health intervention. They described how the broadening of the definitions to include AHSS might be a natural next step, building on the R\&D structures and culture that already exists within their firms. For Stefanie Nickel, Head of Diversity and Inclusion at Novartis, the broad Frascati definition of ' $R \& D$ makes sense. Similarities with pharma $R \& D$ work ... it embodies a discipline and globally aligned approaches, at least in the clinical side, and that could benefit us. It could also mean much upfront investment in research, rather than only focusing on development.'

${ }^{42}$ Bird et al. (2020). 


\section{Using social science R\&D for businesses with social missions}

Zinc is a company set up by the London School of Economics (LSE) that aims to encourage businesses to use social science, design and technology to solve social problems in the developed world. Zinc has a portfolio of 35 technology-based companies that work on specific social rather than purely commercial missions.

For example, they have helped set up transport Tandem, a taxi-ride sharing platform to reduce transport poverty. The venture-founders had read research studies showing that many people in poverty in big UK cities cannot secure jobs because they have no way of getting to places of work. The platform is like Uber but is aimed at reducing the cost of a taxi to the same price as a bus. They have ongoing research projects which aim to enhance knowledge of consumer behaviour for an innovative service.

R\&D is a core part of their way of working, applying existing social science knowledge to the businesses, as well as generating novel R\&D insights. As Zinc's Chief Scientist, Rachel Carey, who has a PhD in psychology, explained 'We need bits that are solid [from existing social science], and bits that need testing [by conducting original studies or replicating previous research], building on research and data out there:

Dr Carey singles out two aspects of the Frascati R\&D definition as working for her business: firstly, that it reflects the contribution R\&D makes to new knowledge; and, secondly, the application of this new knowledge to devising applications. Zinc are committed to building feedback loops between research and business development 'It is not a one-way funnel of evidence to business', says Dr Carey, 'but about knowledge exchange, using experiments'.

She sees the value generated as not just for businesses, but for social science researchers too: 'Early stage start-ups are super-interesting territory for social sciences as start-ups experiments in themselves. But in most businesses there are no really systematic approaches to capture that learning. What Zinc seeks is to understand what works, what sticks. The role of R\&D at Zinc is grounded in science and science-rich'. Zinc has an open science approach so that they share everything on a general level, but not at the level of individual ventures to avoid sharing commercially or personally sensitive material.

\section{Uncertainty, knowledge exchange, and evidence-based business}

As discussed earlier, the resolution of uncertainty is one of the five defining requirements of the Frascati Manual definition. ${ }^{43}$ And part of that uncertainty is not knowing how something that seems to work in one setting might work in another (its external validity). This means that new approaches and hypotheses have to be repeatedly tested in the real world. According to Mike Hughes, from Ogilvy Consulting, the innovation arm of the advertising, marketing, and public relations agency, creative businesses need to engage in applied learning and research. 'We need strategy for learning from others, beyond testing in a lab environment, but we don't want to spend lots of time testing whether our hypothesis is true or not'. He believes pace and rapid

${ }^{43}$ OECD (2015: 45). 
iterations are important. According to Hughes, the R\&D process needs to 'test if it works and then roll out to scale...including testing counterintuitive ideas'. Hughes said that this advantages digital products where propositions can be tested more easily. 'Following clicks is also a more reliable way of following consumer behaviour ... compared to previous means like focus groups, where there could be biases in reported behaviour.' ${ }^{\text {44 }}$

The Frascati definition of $R \& D$ emphasises the creation of original research. Knowledge exchange differs in stressing the sharing of existing research. In our interviews, such distinctions were not always clear cut. Some interviewees tended to discuss both at the same time. AHSS R\&D in business could involve the synthesis and exploitation of existing evidence - but through the 'original' method of conducting a synthesis of published research. Some of our interviewees revealed a different way of seeing R\&D within businesses: evidence-based business and management. This is the practice of encouraging decision-making to adopt - and develop - the best available research and critical thinking. ${ }^{45}$ Evidence may come from social scientific research, as well as codified internal business information, and even from tacit professional experience. The evidence may involve conducting original studies to change and test business practices, such as experimental research to test hypotheses on different ways of improving staff performance, or a new synthesis of the best available research through Systematic Reviews and Rapid Evidence Assessments. Such reviews and evidence assessments of research are not usually defined as 'pure' or 'applied' research in the Frascati Manual R\&D definition ${ }^{46}$ - but they are vital parts of developing our knowledge, and then improving business practice and productivity.

An example of the overlap between evidence-based business and R\&D can be seen in the work of the consultancy Advanced Workplace Associates (AWA) who have been working with a range of companies, including banks and accountancy firms, to find and test the best 'cognitive fitness', such as sleep, movement and air quality to improve business effectiveness and efficiency. In addition to carrying out a Rapid Evidence Assessment and translating it into useful outputs, AWA is running trials inside businesses to apply the results of the research to see if they can discern differences in performance.

\footnotetext{
${ }^{44}$ See Bakhshi (2015) for this argument in the book publishing industry.

${ }^{45}$ Rousseau (2012).

${ }^{46}$ OECD (2015: 50-1).
} 


\section{Boundaries between R\&D and market research}

Our interviews with businesses suggest that there are important boundaries between $\mathrm{R} \& \mathrm{D}$ and market research which are worthy of further exploration, and have particular implications for AHSS R\&D. Some of the work we found through our interviews could be historically classified as related to market research - understanding consumer behaviour and the climate that businesses operate in. Market research firms are themselves part of the services sector. ${ }^{47}$ But according to the Frascati definition, market research should specifically be excluded from $R \& D$ even if it is part of the innovation process. ${ }^{48}$ In the UK, BEIS guidelines on R\&D exclude, for example, software development for market research - unless it can show that it has advanced the whole field of software and computer science. ${ }^{49}$ However, some market research we reviewed in this study is experimental and methodologically sophisticated (see box below on Relative Insight) and satisfies the five OECD R\&D criteria: novelty; creativity; uncertainty; systematic; and transferability / reproducibility.

R\&D can feed into business development through understanding wider social trends that impact on markets: 'Understanding of cultures ... all that goes behind the customer transaction with a company, has much greater recognition in our clients, according to Chris Loxley, Head of Research at the start-up consultancy LovedBy who apply behavioural science and 'nudge theory' to businesses like Lloyds Bank, Cambridge Assessment OCR examination body, and AXA insurance. 'There is more awareness of $R \& D$ that is sensitive to the value of social scientific insight,' said Dr Loxley,

\section{Beyond market research: using latest techniques to help grow global media firms}

Ampere Analysis uses cutting edge data analysis of the media and entertainment for Hollywood and global media content firms. They have used machine learning and new data sources to replace traditional audience monitoring and sampling methodologies. The data they create is then used for new software, and some of the products are marketed to businesses who purchase their data products and software. According to Richard Broughton, Executive Director at Ampere Analysis, UK R\&D tax relief has 'worked well for them', although the funding tends to be focused on tangible things like software, rather than helping with the research. 'The majority of what we do is research,' says Broughton. 'It might be data ... essentially trying to create new ways of looking at industry - media and entertainment sector. So the [OECD Frascati] definition makes sense to me ... but the $R \& D$ tax credit scheme is more about tech development for us.' Some interviewees stressed that the tax relief scheme has biased them to focus on products like software, even though a time-consuming and valued part of the work was the research that fed into the products and services.

\footnotetext{
${ }^{47}$ ONS (2019a).

${ }^{48}$ OECD (2015: 60).

${ }^{49}$ BIS (2010), section D2.
} 
'and sometimes it is pleasant surprise for me to have to sell it, as it can sound very academic and high level but a lot of our clients need it to get beyond traditional market research.'

\section{AHSS R\&D has value but is often perceived as less 'tangible'}

Many interviewees highlighted the need for greater awareness of what AHSS R\&D is, and the value it brings. As Sarah Ellis at the Royal Shakespeare Company noted:

There is a lot of misunderstanding. R\&D is generally not aligned to arts and creative models. So there needs to be a wider understanding of the many ways R\&D can be approached to deliver a diverse range of outcomes so that it can bring greater value to UK Plc. Currently, there needs to be a lot of manufactured certainty, which is not the only aspect of R\&D, it is also about new systems and models achieved through exploration and collaboration, so not about just one output, but a range of wider, broader impacts as well as specific outcomes or deliverables. It is important and very complex. It needs system and people thinking as well as product thinking.

One reason why measuring value from AHSS R\&D is challenging is because it is perceived to be less tangible than STEM R\&D, and it has different applications. As one interviewee noted

\section{The Royal Shakespeare Company enterprise arm creating the Audience of the Future}

The Royal Shakespeare Company (RSC), through its enterprise arm, is working with 14 academic partners to bring social science, arts, and humanities research into their performances. Through a UKRI-funded R\&D demonstrator programme, the Audience of the Future, the RSC is undertaking applied research and experimental development on audiences to create new ways of working and to open up the process of creating performances. The RSC has embarked on this to 'open the doors to researchers'. As Sarah Ellis, the RSC's Director of Digital Development, said 'Arts, humanities and social science researchers ask the right questions, but aren't necessarily the right people to lead the work. We need to build partnerships between industry and researchers. It is about getting the alchemy there. It takes time. There is a lot of time front loading to get the relationship going. It pays off, you get the outcomes. Research has a big and important role.'

At the RSC, and potentially more broadly in the creative industries, R\&D provides a structure for exploration and innovation. Value is captured from the work the RSC put on the stage, with value accruing to the brand, and through ticket sales, and reach. Sarah Ellis says:

'When we are looking at the Audience of the Future, we are looking at the next 5 years, we look at the success of the project, organisational transformation, and impacts on the wider culture sector, the impacts of tools for the sector, and new tech. But they will not have returns for years, so we also need to create quick wins. We sometimes hand over the baton, where someone else delivers it on, but then that is harder to define and track impacts. The practitioner is very present tense, and the researcher and the tech company are always thinking about the future. This creates tension but also a useful dynamic.' 
Often [there is] a tangible difference between businesses utilising R\&D from AHSS and the way they do from hard science. Hard science is more concrete. Whereas arts and humanities is a more creative process, the innovation process itself, and the process is just as important as the end goal.

Part of the value comes from the creation of tacit expertise and uncodified knowledge. Rachel Carey, Chief Scientist at Zinc told us:

In the social sciences, the value tends to be less in 'an idea', and more in a set of skills and methodologies that can be iteratively applied. The innovation system from the life sciences, and the models that were developed for 'pills and widgets', cannot be easily translated to the social sciences. R\&D in the AHSS has the potential to be vibrant and dynamic, but we need to approach it fundamentally differently.

Using Intellectual Property (IP) as a way to create value was also thought to be challenging for AHSS R\&D by many of our interviewees. Interviewees were skeptical about translating an IP model of R\&D from areas like manufacturing, pharmaceuticals, engineering, and science, to sectors relevant to AHSS. Rather than a clearly defined patent or even copyright, the real value came from development of method, often incremental. Rachel Carey, chief scientist at Zinc told us:

the value comes from the way to learn more effectively and quickly, rather than starting up having to pivot a new business with no formal learning, you are more optimised by using formal experiments. It is different from the world of pills and widgets - and it is wrong to see it as an idea $[R \& D]$ that you can translate from life sciences to social sciences. IP and ideas are not so valuable in my field, it's more about expertise and methods in social science, so harder to show financial value. You are learning more efficiently and more quickly.

However, not all businesses we interviewed were skeptical as to the importance of IP and felt it to be a necessary part of exploiting R\&D. In Pearson Plc, R\&D is valued by the intellectual property (IP) it generates. Sandy Smith, Vice President, Efficacy \& Research at Pearson Plc says 'from a corporate perspective, you'd think about $R \& D$ in terms of IP, and what it enables us to do. It is about functionality more than just in terms of the "stock of knowledge".'

One other way of quantifying value was through the commitment to staff costs for researchers. Most of the companies we interviewed had invested considerable resources into recruiting expertise to help their business conduct R\&D. However, a number expressed concerns about the difficulties of recruiting staff with $\mathrm{PhDs}$ and advanced research skills in the UK, singling out shortages of talent with psychology and behavioural science skills in particular. As some of the interviewees told us, they are competing with the Big Tech companies like Facebook, Google, Uber and others are hiring many new post-graduates in these disciplines. 


\section{UK businesses applying for the UK R\&D Tax Credit when undertaking AHSS R\&D}

As AHSS R\&D is explicitly excluded from the definition of R\&D used by the UK tax authorities for tax relief purposes, we were surprised to learn that the businesses we spoke with were successfully claiming against it. As an example, the Royal Shakespeare Company claims R\&D tax relief for some of its live content. Sarah Ellis describes the tax relief as 'incredibly important' as it enables the RSC to 'offset the risk, allow us to innovate confidently, and give us a baseline.' But the RSC encounters problems when applying for it. Sarah explains:

Being a large organisation doesn't mean that we don't need to look at the risks we take. We [the RSC] are in the same band as Rolls Royce and there isn't parity. We still take risks, and there is still operational and financial risk. You still need the support even though you're large. You are in an ecosystem here you need a robust business model, but you need R\&D to push you forward.

Some of those we interviewed said that R\&D tax relief incentivised businesses to stress test products where the embodiment of technology was clearer. Even where this extended to something like software and applications, definitions were seen as problematic. Jenny Tragner, an adviser at the R\&D tax consultancy ForrestBrown who has advised many firms and is a member of HMRC's R\&D Consultative Committee said:

In terms of R\&D tax reliefs, software is technology, therefore work which advances software capability as a whole can be $R \& D$, however routine software development which facilitates a creatively innovative project does not qualify. In practice, the bar for demonstrating that a software project has advanced over capability in the field of computer science is high. In addition, the wider creative activities in such projects do not attract relief, only the actual generation of the software.

However, many relayed how valuable they had found the tax relief for research. Ben Hookway, Chief Executive of Relative Insight, a data analytics consultancy spun out of Lancaster University, says that the tax relief can play a vital role in early stages of R\&D. Much of their tax credit went to fund staff working in product development but a small proportion was still used on advancing research:

It makes a difference; it is not an insubstantial amount of money at certain stages of company development. Although we have now had substantial venture capital investment, $£ 20 \mathrm{~K}$ or $£ 50 \mathrm{~K}$ tax credit when we were at an early stage, and we were resource intensive in our R\&D, a $£ 50 \mathrm{~K}$ tax credit was the difference between 5 months survival or not; it can be critical. But firms can overly rely on it. If you don't get it, or get it in time, it can be damaging if you're doing your financial planning around it. 


\section{Businesses engaged in AHSS R\&D can help achieve social and environmental impact}

Beyond efforts to tackle the COVID-19 pandemic, some of the interviewees communicated the value of R\&D in helping them to address social and environmental changes. Despite being commercial businesses, some of our interviewees were very passionate about their commitment to using $\mathrm{R} \& \mathrm{D}$ for social and environmental good, such as using research insights to reduce inequality or environmental impact.

According to this narrative, companies - and the UK economy - cannot keep still and must have an eye on the future, both in terms of technology, but also disruptive social changes. AHSS research can help businesses understand social trends - such as the \#MeToo movement or Black Lives Matter - so that their products are socially responsible. The interviewee from Unilever said that AHSS R\&D is needed because there are 'enormous societal changes and you have to be in tune with those trends and seek to anticipate all that lies ahead'.

\section{Businesses working with AHSS R\&D need government support}

When the interviews were conducted the UK was in the middle of the first national COVID-19 'lockdown'. Unsurprisingly, the crisis was having a big impact on many companies and their future plans for R\&D. Some interviewees said that their plans were likely to be curtailed or stopped completely in the short and medium term because of the economic uncertainties, although others were still growing their R\&D budgets, particularly in the digital area.

Some of the UK businesses we interviewed were clear that government support for AHSS R\&D was essential, both through R\&D tax relief, and by other policy interventions. It was recognised that the UK needed to 'innovate out' of the economic crisis, with $R \& D$ more generally ever more important, but that $R \& D$ was at risk of being cut by businesses without further public support. An implication was that the Government should explore whether and in what ways an expanded definition of R\&D might help with the economic recovery and other government priorities as the nation rebuilds from the pandemic.

\section{Recommendations for policymakers, funders and business}

This paper has reviewed key policy publications and has presented the findings of qualitative interviews with businesses and other organisations involved in $\mathrm{R} \& \mathrm{D}$. We propose five key recommendations. 
1. Government policy should more explicitly recognise AHSS R\&D, both in R\&D tax incentives, and in public investment such as in Innovate UK and other UK Research \& Innovation (UKRI) bodies. ${ }^{50}$ The interconnectedness of AHSS and STEM R\&D calls for greater coordination across different parts of the research funding landscape.

2. While BEIS, HMT and HMRC naturally have their own perspectives on R\&D, there is a need for a coordinated strategic approach to how the definition of R\&D is implemented in the UK. This definition should acknowledge the role of AHSS in the research and innovation system.

3. The ONS should work with the British Academy and other key stakeholders to conduct a thorough review of the different ways in which it collects R\&D statistics to ensure the scope is fully inclusive of AHSS R\&D, as consistent with the internationally agreed Frascati Manual. This should include ensuring that its survey guidance encourages businesses to give an accurate and inclusive account of their AHSS R\&D expenditures.

4. The UK should learn from international differences in implementation of the OECD's Frascati Manual R\&D definition in tax incentives schemes. For example, some countries like France, Italy, Russia, and South Korea recognise Social Science and Humanities R\&D within their R\&D definitions for Tax Relief.

5. There needs to be a greater recognition and awareness of the breadth of activities and disciplines captured under R\&D by policymakers, funders and industry, including AHSS. This system change will required a coordinated response and will not happen overnight, but it is essential if the UK is to maximise the contribution that R\&D can make to innovation and productivity growth.

\section{Acknowledgements}

We would like to thank the British Academy for its funding of this research, and Harriet Barnes, Sarah Cowen and Dr Molly Morgan-Jones for their valuable suggestions in all stages of the study. Comments from an anonymous reviewer materially improved the paper.

\footnotetext{
${ }^{50}$ The Campaign for Social Sciences in 2015 has called for 'the Treasury and HMRC to examine the way the R\&D tax regime recognises social-science-derived innovations in organisational processes. If "commercialisation of insights and inventions has been historically weak in the UK", the application of social-science-derived thinking and practice in firms, in the training of managers and in industrial "clusters", is vital in strengthening the link between innovation and exploitation' Walker (2015).
} 


\section{References}

Athow, J. (2019), 'Everybody's heard about the GERD - measuring measures R\&D spending at ONS' (ONS blog).

Bakhshi, H. (2015), 'The Age of Experimentation', Copyright Framework Position Paper (CREATe). https://www.create.ac.uk/research-programme/theme-4/wp4d-whose-book-is-it-anyway-ipcollaborative-business-models-and-questions-of-ethics-and-creativity-in-digital-publishing/copyrightframework-position-papers/hasan-bakhshi-position-paper/

Bakhshi, H. \& Lomas, E. (2017), Defining $R \& D$ for the creative industries, policy briefing (London, Nesta).

Bakhshi, H., Breckon, J. \& Puttick, R. (2021), Business R\&D in the Arts, Humanities and Social Sciences (London, Nesta and The Creative Industries Policy \& Evidence Centre). https://pec.ac.uk/assets/ publications/Policy-briefing_-RD-in-the-arts-humanities-and-social-sciences.pdf

Bakhshi, H., Schneider, P. \& Walker, C. (2008), Arts and Humanities Research and Innovation (London, Nesta, UCL \& AHRC).

Bakhshi, H., Schneider, P. \& Walker, C. (2009), 'Arts and Humanities Research in the Innovation System: the UK Example', Cultural Science, 2(1). https://doi.org/10.5334/csci.19

Balawejder F. \& Monahan, E. (2020), Effective Policy Approaches to Sectoral Issues (Industrial Strategy Council).

BEIS (Department for Business, Energy \& Industrial Strategy) (2020), UK Innovation Survey 2019: Headline findings covering the survey period 2016-2018 (BEIS).

Bird, G., Gorry, H., Roper, S. \& Love, J. (2020), R\&D in the Creative Industries Survey - 2020: Research report prepared for DCMS (OMB Research).

BIS (Department for Business, Innovation and Skills) (2010), Guidelines on the Meaning of Research and Development for Tax Purposes (BIS).

British Academy (2020), Qualified for the Future: Quantifying demand for arts, humanities and social science skills (London, British Academy).

Creative Industries Council (2020), Creative Industries Transition and Recovery Plan (London, Creative Industries Council).

d'Angelo, C., Knack, A., MacLure, C. \& Freeman, J. (2018), Evidence synthesis on the conditions needed to translate research and drive innovation (RAND). https://doi.org/10.7249/RR2610.2

Design Council (2018), The Design Economy 2018: The state of design in the UK (London, Design Council).

Goodridge, P., Haskel, J. \& Wallis, G. (2014), UK Innovation Index 2014 (Nesta Working Paper, 14/07).

Higgins, J. \& Green, S. (eds) (2008), Cochrane handbook for systematic reviews of interventions, Version 5.0.0 (London, The Cochrane Collaboration). https://doi.org/10.1002/9780470712184

HM Government (2010), Corporation Tax Act 2010, s1138.

HM Government (2017), Industrial Strategy: Building a Britain fit for the future.

HM Government (2020), UK Research and Development Roadmap.

HMRC (HM Revenue \& Customs) (2015), Guidance: Research and development tax relief; Making R\&D Easier for Small companies.

HMRC (2019), Research and Development Tax Credits Statistics: October 2019 (London). https://webarchive. nationalarchives.gov.uk/20200711085916/https://www.gov.uk/government/statistics/corporate-taxresearch-and-development-tax-credit

HM Treasury \& HMRC (2020), The scope of qualifying expenditures for $R \& D$ Tax Credits: consultation.

Kahn, M. (2010), 'Measure for measure: quantifying the social sciences', in World Social Science Report 2010: Knowledge Divides (Unesco and International Social Science Council), p. 361. 
Lenihan, A., Witherspoon, S. \& Alexander, R. (2020), Vital Business: The essential role of the social sciences in the UK private sector (London, Academy of Social Sciences/SAGE).

Morgan Jones, M., Abrams, D., \& Lahiri, A. (2020), 'Shape the future: how the social sciences, humanities and the arts can SHAPE a positive, post-pandemic future for people, economies and environments', Journal of the British Academy, 8: 167-266. https://doi.org/10.5871/jba/008.167

Nesta (2006), The Innovation Gap: Why policy needs to reflect the reality of innovation in the UK(London, Nesta).

Nesta (2007), Hidden Innovation: How innovation happens in six 'low innovation' sectors (London, Nesta).

Nesta (2008), Hidden Innovation in the Creative Industries (London, Nesta).

Nesta (2019), Innovation Mapping Now (London, Nesta).

OECD (Organisation for Economic Co-operation and Development) (2015), Frascati Manual 2015 Guidelines for Collecting and Reporting Data on Research and Experimental Development, 7th Edition (Paris, OECD). http://dx.doi.org/10.1787/9789264239012-en

OECD (2019), Compendium of R\&D Tax Incentive Schemes: OECD Countries and Selected Economies, 2018 (Paris, OECD).

OECD \& Eurostat (2019), Oslo Manual 2018: Guidelines for Collecting, Reporting and Using Data on Innovation, 4th Edition (Luxembourg, Eurostat). https://doi.org/10.1787/9789264304604-en

ONS (Office for National Statistics) (2019a), 'Services sector, UK: 2008 to 2018' (ONS).

ONS (2019b), 'Research and development expenditure' (ONS).

ONS (2019c), 'Statistical Bulletin: Business enterprise research and development, UK: 2018' (ONS).

ONS (2020a), UK National Accounts, The Blue Book: 2020 (ONS).

ONS (2020b), 'Gross domestic expenditure on research and development, UK: 2018'(ONS).

ONS (2020c), 'Expenditure on research and development performed in UK businesses, SIC 72: 2018' (ONS).

Rousseau, D.M. (ed.) (2012), The Oxford Handbook of Evidence-Based Management (New York, Oxford University Press). https://doi.org/10.1093/oxfordhb/9780199763986.001.0001

Walker, D. (2015), The Business of People (London, Campaign for Social Science/SAGE).

\section{Appendix: Interviewees}

We are hugely grateful to the individuals from companies who generously shared their experiences and expertise with us. These individuals are:

1. Richard Broughton, Executive Director, Ampere Analysis

2. Colin Campbell, CEO and Founder, Unlocking Potential

3. Rachel Carey, Chief Scientist, Zinc

4. Ben Hookway, Chief Executive, Relative Insight

5. Mike Hughes, Behavioural Strategist, Ogilvy Consultancy

6. Phil Jones, Managing Director, Wired Sussex

7. Chris Loxley, Head of Research, LovedBy

8. Sandy Smith, Vice President, Efficacy \& Research, Global Product, Pearson

9. Keith Rutherford, Vice-President R\&D Home and Hygiene at Unilever

10. Sam Gallagher, Principal Consultant, Oxentia

11. Stefanie Nickel, Head of Diversity and Inclusion, Novartis 
12. Andrew Mawson, Founding Director; Karen Plumb, Director of R\&D, Advanced Workplace Associates (interviewed together)

13. Michael Tougher, CEO, SoundBops

As well as these interviews with businesses organisations, we would also like to thank the following for their time speaking to us:

1. Silvia Appelt, Economist, S\&T indicators unit, OECD

2. Eric Barends, Managing Director, Centre for Evidence-Based Management

3. Professor Julia Black, Strategic Director of Innovation, LSE

4. James Byford, Lead Enterprise Tutor, Chelsea Football Club Foundation

5. Nida Broughton, Director of Economic Policy, Behavioural Insights Team

6. Sarah Ellis, Director of Digital Development, Royal Shakespeare Company

7. Anne Fraser, Enterprise Manager, Royal Society of Edinburgh

8. Fernando Galindo-Rueda, Senior Economist, Economic Analysis and Statistics Division, OECD

9. Jonny Gifford, Senior Advisor for Organisational Behaviour, Chartered Institute for Professional Development

10. Mark Mann, Principal Licensing \& Ventures Manager, Oxford University Innovation

11. Jon Page, Head of Operations, BBC R\&D

12. Jenny Tragner, Director, ForrestBrown R\&D Tax consultants

13. Sharon Witherspoon, Head of Policy, Academy of Social Sciences

14. Nicole Yershon, Consultant, The NY Collective

\section{Note on the authors}

Hasan Bakhshi is Principal Investigator and Director of the AHRC's Creative Industries Policy and Evidence Centre. He is an economist by training and has published widely on topics ranging from measurement to technological change and the economics of the creative and cultural sector. Recent publications include: 'Measuring the creative economy', in T. Bille, A. Mignosa \& R. Towse (eds), Teaching Cultural Economics (Edward Elgar, 2020); 'The creative industries and industrial policy: The UK case', in S. Cunningham \& T. Flew (eds), A Research Agenda for the Creative Industries (Edward Elgar, 2019); 'Digital Research and Development in the Arts', in V. Ateca-Amestoy et al. (eds), Enhancing Participation in the Arts in the EU (Springer International, 2017). 
Jonathan Breckon is an independent consultant working on research and evidence use. He was formerly Director of Nesta's Alliance for Useful Evidence for nine years, a network that champions that promotes the smarter use of evidence in social policy and practice. Previously Director of Policy and Public Affairs at the Arts and Humanities Research Council, his research interests cover politics and psychology, including the relationship between research and policymaking. Publications include: 'The Experimenter's Inventory: A catalogue of experiments for decision-makers and professionals' (2020); 'Bodies of Evidence; How professional organisations in health, education and policing champion the use of research' (2019); 'Using Evidence in the UK', in What Works Now: Evidence-Informed Policy and Practice (Policy Press, 2019).

Ruth Puttick is a Senior Associate at Nesta, runs a research consultancy, and is in the final stages of a PhD in political science and urban studies. She previously worked at Nesta, leading large studies into public and social innovation. More recently she was at the global management consultancy, Tony Blair Associates, where she helped establish and manage the policy and research team in the government advisory practice. She has written extensively on government innovation, reform and impact, and acts as an advisor to a range of governments, philanthropic foundations, charities and think tanks. Recent publications include: 'Assessing the Potential of Mini-publics to Promote Evidence Uptake in Social Policy and Practice' (2018); 'Mapping the Standards of Evidence Used in UK Social Policy' (2018); and 'COVID 19 and Democracy and Citizen Participation in the UK' (2020).

To cite the article: Hasan Bakhshi, Jonathan Breckon and Ruth Puttick (2021), 'Understanding R\&D in the arts, humanities and social sciences', Journal of the British Academy, 9: 115-145.

DOI https://doi.org/10.5871/jba/009.115 
